\title{
A relação entre Design e Artesanato na valorização da cultura local: Representação e aprendizado entre estudantes e artesãs (Maranhão, Brasil) ${ }^{1}$
}

\author{
La relación entre Diseño y Artesanía en la valorizacíon de la cultura \\ local: Representación y aprendizaje entre estudiantes y artesanas \\ (Maranhão, Brasil)
}

\section{Relationship between Design and Handicraft for the valorization of local culture: Representation and learning among students and artisans (Maranhão, Brasil)}

\author{
João Matheus de Barros Câmara² \\ Sâmio Lucas Pachêco Barbosa ${ }^{3}$
}

\begin{abstract}
Resumo
Este artigo apresenta o processo de integração, aprendizado e trabalho entre estudantes e artesãs nas cidades de São José de Ribamar e São Luís, no Maranhão (Brasil). Foram realizados encontros e oficinas de aprendizado e representação sobre manifestações no contexto afro maranhense e práticas sobre construção de objetos em cerâmica, buscando aproximar universidade e comunidade, proporcionar alternativas de produção artesanal e experimentar ferramentas de reconhecimento e criatividade para a valorização da cultura local. Utilizando o metaprojeto como metodologia, os saberes das artesãs e técnicas de compreensão, análise e a prática de desenhos para nortear o projeto, os envolvidos no processo conseguiram construir novos produtos e identidades visuais, colaborando com a difusão do artesanato na comunidade e no reconhecimento de patrimônios culturais imateriais, como o Tambor de Crioula. Uma experiência educacional e cultural que também pode ser realizada em outros contextos.
\end{abstract}

Palavras-Chave: Design; Artesanato; Aprendizado; Cultura; Tambor de Crioula.

\section{Resumen}

Este artículo presenta el proceso de integración, aprendizaje y trabajo entre estudiantes y artesanas en las ciudades de São José de Ribamar y São Luís, en Maranhão (Brasil). Se realizaron reuniones y talleres de aprendizaje y representación sobre manifestaciones en el contexto afro maranhense y prácticas sobre la construcción de objetos en cerámica, buscando acercar universidad y comunidad, proporcionar alternativas para la producción artesanal y experimentar herramientas de reconocimiento y creatividad para valorar la cultura local. Utilizando el metaproyecto como metodología, el conocimiento de las artesanas y las técnicas de comprensión, análisis y práctica de dibujos para guiar el proyecto, los involucrados en el proceso pudieron construir nuevos productos e identidades visuales, colaborando con la difusión de la artesanía en la comunidad y

\footnotetext{
1 Artigo apresentado no II Congresso Internacional Online de Estudos sobre Culturas, na modalidade online, 2020.

2 Graduando em Design; Universidade Federal do Maranhão - UFMA; São Luís, Maranhão, Brasil; joaomatheus98@gmail.com.

3 Graduando em Design; Universidade Federal do Maranhão - UFMA; São Luís, Maranhão, Brasil; pachecosamio@gmail.com.
} 
en el reconocimiento de patrimonio cultural inmaterial, como el Tambor de Crioula. Una experiencia educativa y cultural que también se puede llevar a cabo en otros contextos.

Palabras claves: Design; Artesanía; Aprendizaje; Cultura; Tambor de Crioula.

\begin{abstract}
This article presents the process of integration, learning and work between students and artisans in the cities of São José de Ribamar and São Luís, in Maranhão (Brazil). Learning and representation meetings and workshops were held on demonstrations in the afro maranhense context and practices on the construction of ceramic objects, seeking to approach university and community, provide alternatives for artisanal production and experiment recognition and creativity tools for valuing local culture. Using the metaproject as a methodology, the artisans knowledge and techniques of understanding, analysis and practice of drawings to guide the project, those involved in the process were able to build new products and visual identities, collaborating with the dissemination of handicrafts in the community and the recognition of immaterial cultural heritage, such as Tambor de Crioula. An educational and cultural experience that can also be carried out in other contexts.
\end{abstract}

Keywords: Design; Handicraft; Learning; Culture; Tambor de Crioula.

\title{
1. Introdução
}

Relacionar design e artesanato para colaborar com a cultura local é uma proposta que envolve criatividade, integração social e reconhecimento de diversas manifestações que compõem um contexto social. Através da reflexão sobre a importância da produção artesanal inspirada na história e no imaginário maranhense para gerar renda e representar sentimentos e expectativas do território, professores e alunos da Universidade Federal do Maranhão UFMA integraram-se a um grupo de artesãos em São José de Ribamar - MA, com a proposta de aproximar universidade e comunidade na troca de conhecimentos e oportunidades.

Para conduzir o processo de colaboração entre os envolvidos na iniciativa, foi necessário entender e relacionar técnicas e conhecimentos. De um lado, saberes e repertório das artesãs sobre manifestações e características da cultura afro maranhense e conhecimento tácito do barro, matéria prima do grupo para a produção de peças em cerâmica; e entrelaçado a essa realidade, as ferramentas e informações acadêmicas compartilhadas pela universidade. É nessa relação de respeito e consenso na qual são priorizadas experiências e particularidades dos envolvidos que o aprendizado com intuito de preservação da cultura se efetiva, desenvolvendo produtos autênticos e imagens como forma de representação de um território, possibilitando um modelo de referência a outras comunidades e possíveis clientes e apreciadores interessados. Essas questões são reforçadas por Cohen (1988) quando aponta que

"a autenticidade não é um conceito absoluto, mas intensamente negociado. Artesanato e danças performatizadas [...] podem, ao longo do tempo, tornar-se autênticas. A presença de um novo público externo, os turistas, oferece a oportunidade da incorporação de novos produtos culturais em seu "romance", como mensagens autênticas" (COHEN, 1988, pg. 378). 
Destaca-se durante o projeto a convivência que foi construída de maneira orgânica através do processo educacional e colaborativo, visto que as atividades foram realizadas durante um semestre, além da elaboração gradativa de etapas para identificação de necessidades dos envolvidos e da buscar por alternativas de enaltecimento da cultura local, adquiridas através do repertório das artesãs e outras via pesquisa realizadas durante o percurso. Izabel Matos, líder do grupo de artesãs, teve importante papel para que todos os participantes entendessem o interesse maior do grupo, que era representar e valorizar a cultura maranhense e o Tambor de Crioula (dança e patrimônio imaterial), em produtos e nas identidades produzidas coletivamente com os professores e estudantes.

\section{Reflexão Teórica}

Vários valores foram adquiridos nessa troca de experiências construída ao longo do projeto. Uma delas de alto valor de destaque é o "respeito ao barro", frase repetida diversas vezes por Izabel Matos no que diz respeito ao tempo que matéria prima necessita para “descansar", à gentileza de retirada de pequenas pedras do material, com as mãos, de modo a garantir a qualidade necessária e a adaptação de utensílios como o prato de vidro para facilitar a queima e o movimento para a cerâmica. Estas práticas de cuidado e apreço demonstradas na Figura 1 foram apreendidas por Izabel com seus antepassados, valores estes destacados por Lima (2010) quando afirma que "o artesanato tradicional possui lastro cultural aparente. Um desses valores é ter sido feito por mãos humanas. É sempre irregular. Perfeitamente irregular" (LIMA, 2010, p.42).

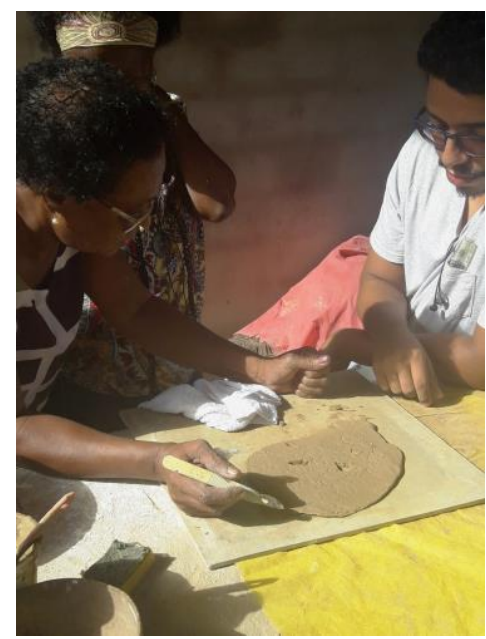

Figura 1 - Líder ceramista Izabel Matos moldando o barro e trocando informações com alunos.

Fonte: Os autores

\subsection{O Tambor de Crioula - Memória e saber cultural}


Através de percepção visual feita nas visitas feitas ao ateliê de produção artesanal foi constatado que Izabel Matos materializava em suas peças o seu depoimento sobre a importância dos saberes adquiridos com sua mãe, avó, bisavó, laços familiares em geral que praticavam as mesmas atividades que ela preservou com os anos. Halbwachs (2006) afirma que as memórias não podem ser percebidas individualmente, mas dentro de todo o contexto social que o indivíduo está inserido, e é dentro do emaranhado de sua raiz afro maranhense que a artesã utiliza o barro de maneira respeitosa e valoriza uma prática cultural representada de forma recorrente em seus trabalhos como mostra a Figura 2, conforme foi exercido por ela e seus familiares: o Tambor de Crioula.

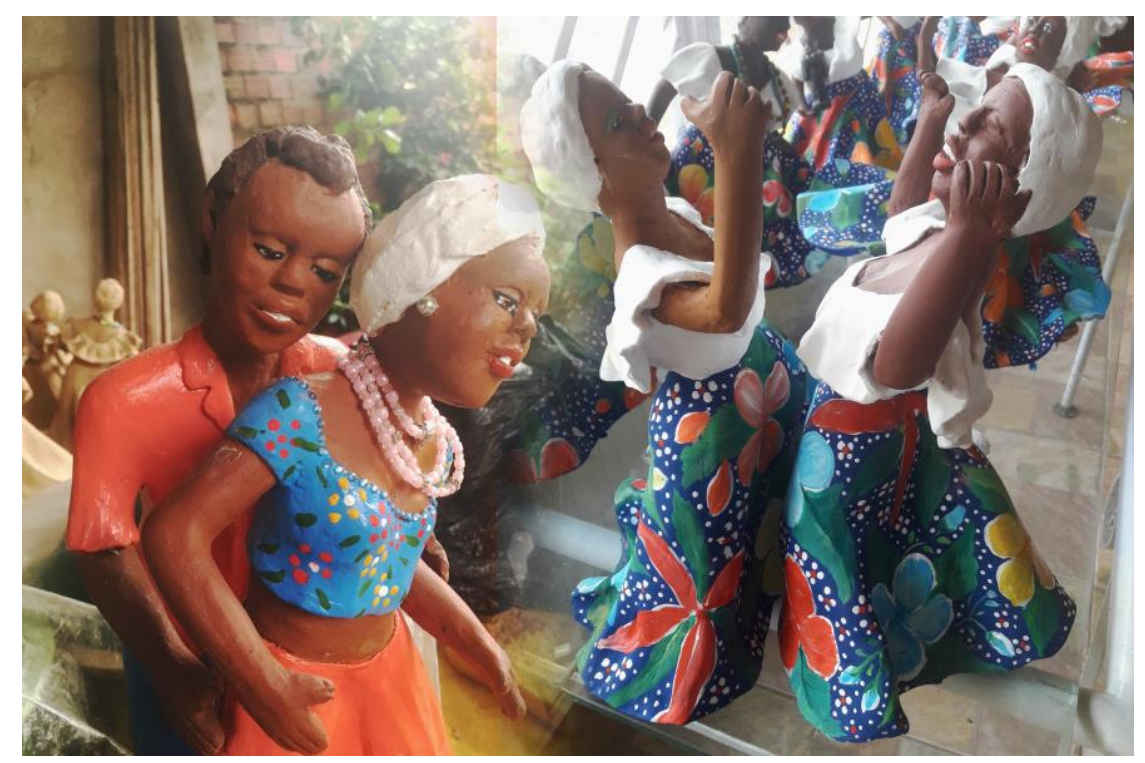

Figura 2 - Peças da artesã representando o Tambor de Crioula.

Fonte: Os autores

Tal atividade se trata de uma dança de origem africana fortemente presente no Estado do Maranhão, da qual participam homens e mulheres, no qual eles são responsáveis por tocar os tambores e elas por dançar. Estas dançarinas são chamadas de "Coreiras" e usam saias de Chita (tecido de algodão com estampas de cores fortes e florais), dançando através de movimentos circulares como representado na Figura 3, indo ao encontro umas às outras em determinados momentos, batendo suas barrigas, em um movimento denominado como "Pungada". Esta popular prática cultural foi a grande fonte de inspiração para o desenvolvimento das propostas do projeto. 


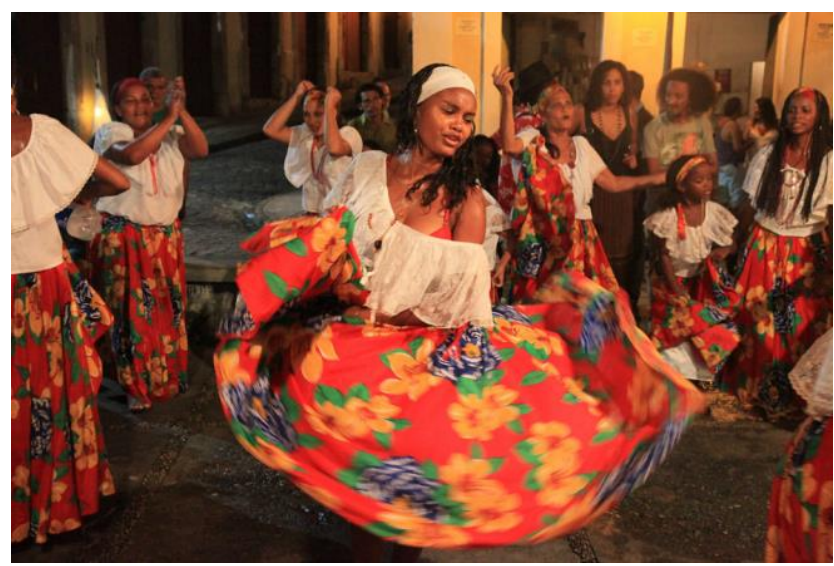

Figura 3 - Peças da artesã representando o Tambor de Crioula.

Fonte: Junior, 2018

\section{Metodologia}

Para realizar o processo foram utilizados os princípios do Metaprojeto segundo Tamekuni (2014), que descreve a metodologia como um conjunto de etapas que não devem ser pré-definidas, evitando limitar e categorizar ações e ferramentas que deverão ser utilizadas. Os estudantes entenderam através da flexibilização do projeto que construir diferentes propostas com as artesãs segundo as limitações e particularidades que surgem gradativamente no trabalho pode ser uma forma viável de relacionar o conhecimento científico com saberes culturais e tradicionais, aproveitando conversas, erros cometidos durante o processo e ideias na escolha, troca e melhoria de técnicas e práticas.

Essas idas e vindas nas fases do projeto aumentaram a riqueza de dedicação das partes envolvidas - Izabel no apreço de se ver representada nos resultados e os alunos em contribuir para a visibilidade de representação de uma mulher afrodescendente e da cultura maranhense - de modo a proporcionar maior troca de conhecimentos de saberes tradicionais e científicos (TAMEKUNI, 2014, pg. 6). 


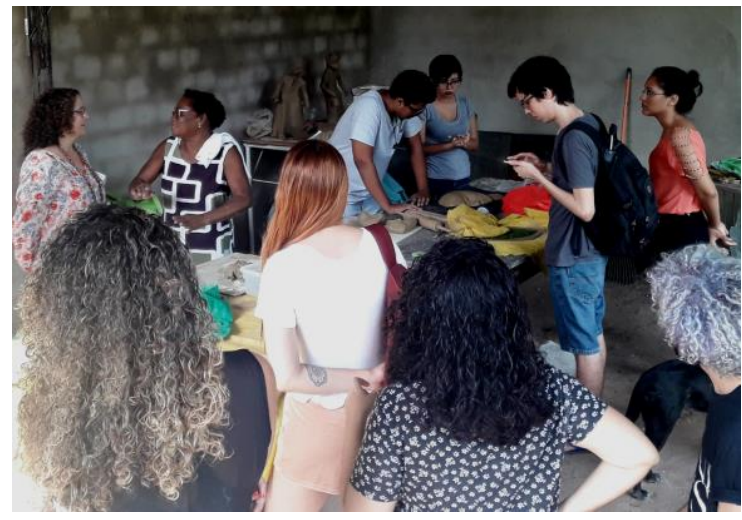

Figura 4 - Integração, diálogos e aprendizado entre estudantes e artesãs.

Fonte: Os autores

Inicialmente, identificou-se como alternativa de valorização do artesanato e geração de oportunidades a construção de produtos em cerâmica utilizando barro do grupo de artesãs e do laboratório da universidade, além de identidades visuais para contribuir com a divulgação e venda dos produtos, representando a cultura afro maranhense. Para facilitar a integração, as atividades foram realizadas tanto no ateliê-sede de Izabel Matos, em São José de Ribamar, quanto na UFMA, em São Luís, e foram identificadas diversas ferramentas para representação e inspiração cultural. Os encontros tiveram momentos de diálogo e oficinas de manuseio e preparação de cerâmicas, observando o que já foi feito pelo grupo, construindo aos poucos as novas alternativas e aplicando ferramentas de criatividade e contextualização como o Mapa Mental, a Definição dos Stakeholders, a Análise SWOT e o Moodboard, detalhados nos próximos tópicos.

\subsection{Mapa Mental}

O mapa mental é um conceito e ferramenta definido por Buzan (2002) como um "caldeirão de criatividade", composto por palavras principais, que podem ser destacadas segundo a importância e frequência de pronúncia, neste caso expressões que surgiram durante os encontros do projeto. Destas palavras principais, devem ser ramificadas palavras secundárias que podem ser escolhidas segundo o critério inicial ou pesquisadas para encontrar inspirações e motivações que colaborem com o aprendizado cultural e os produtos da integração.

As palavras identificadas e escolhidas pelos grupos de estudantes no processo são importantes para entender a contexto cultural do trabalho e iniciar a diversidade nas propostas para as representações (os estudantes foram separados em grupos). Esse mapa pode ser 
organizado graficamente e irá contribuir com alguns aspectos, como definições de cor, formatos, estratégias de divulgação e preservação, entre outros. Um dos modelos preenchidos pode ser visto na Figura 5, que traz os aspectos centrais em torno dos elementos vivenciais de Izabel Matos e suas artesãs sobre a cultura maranhense, estes aspectos possuem características mais externas a eles categorizadas com suas respectivas cores (estas sugeridas pelos participantes em consenso).

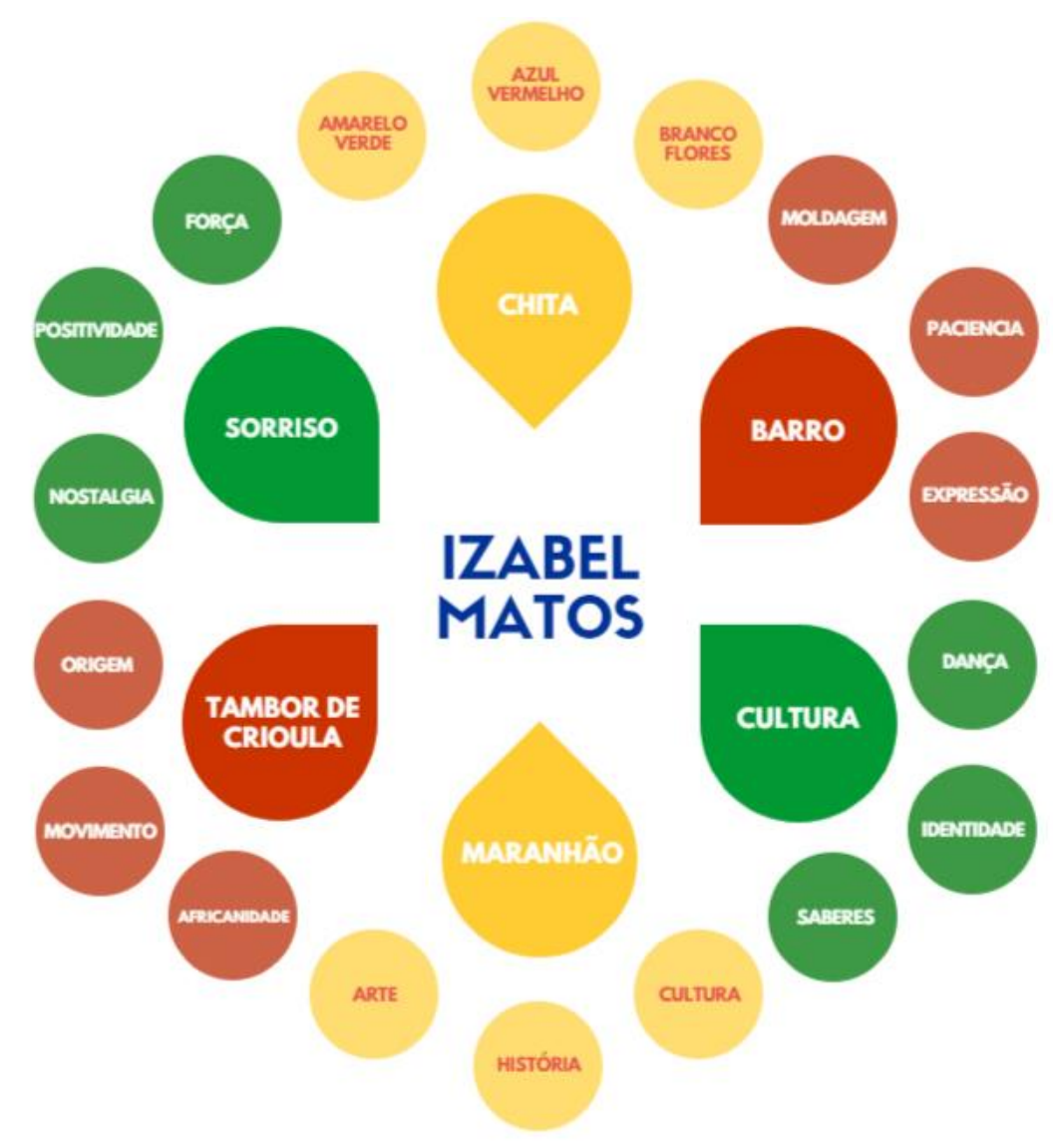

Figura 5 - Mapa mental das vivências de Izabel Matos e artesãs colaboradoras.

Fonte: Os autores

\subsection{Definição dos Stakeholders}

Essa ferramenta é composta por tópicos que buscam identificar todos os indivíduos, as instituições e processos que permeiam uma produção ou sistema e suas questões sociais, informações definidas por Tapscott \& Ticoll (2005) como “interesses e interessados" nas características culturais e econômicas que envolvem comunidades e grupos. Esses tópicos foram preenchidos através de observação, diálogos e pesquisas sobre dados ainda não conhecidos em torno no meio de produção das artesãs, conforme a Figura 6. Assim é possível 
compreender todas as entradas, saídas e relações de um sistema cultural e artesanal, neste caso, a produção de Izabel Matos, possibilitando a geração de oportunidades para a mesma.

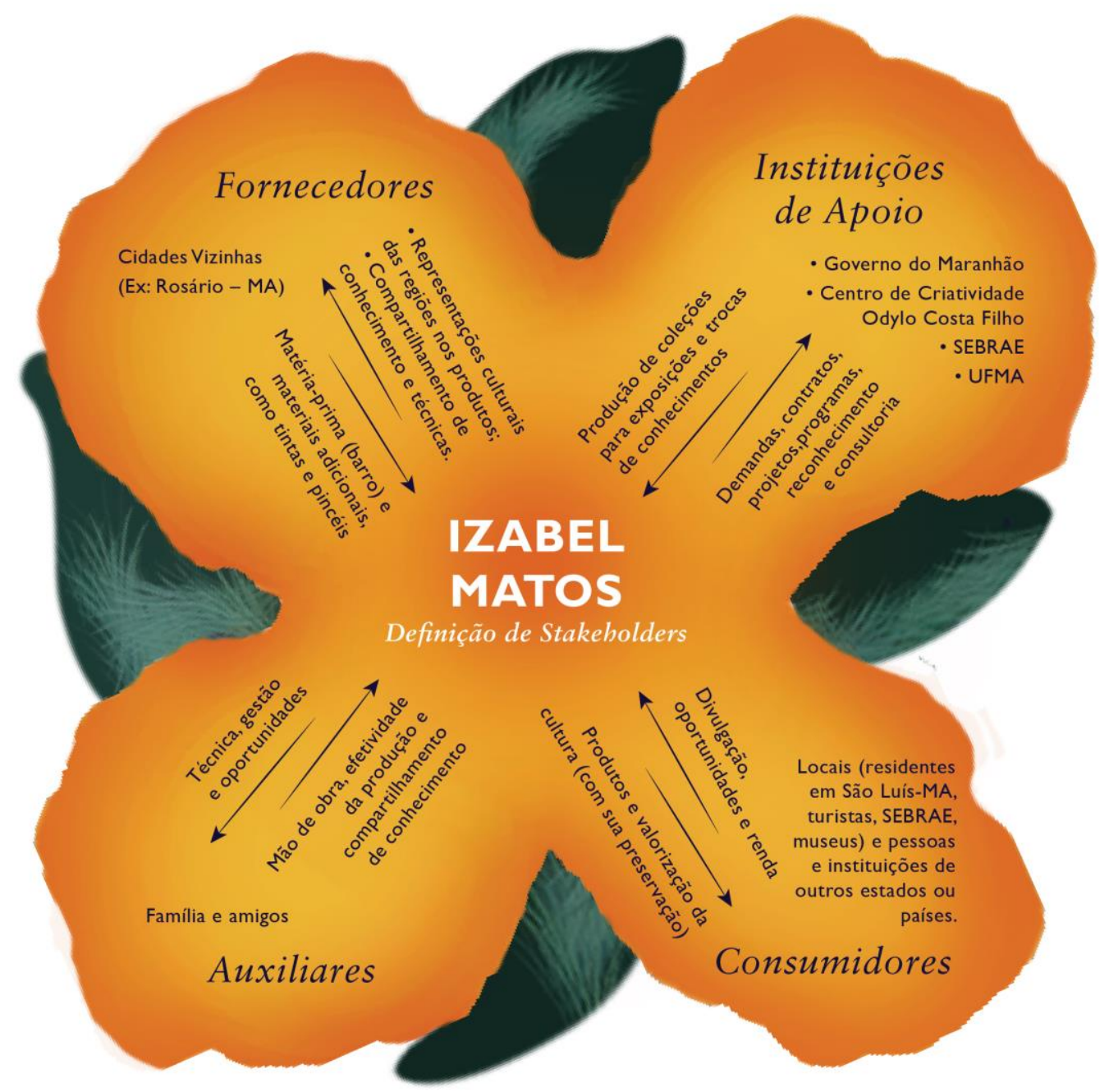

Figura 6 - Definição de Stakeholders construído em formato de uma flor, em referência ao tecido de Chita das saias das dançarinas do Tambor de Crioula.

Fonte: Os autores

\subsection{Análise SWOT}

Nesta análise é possível explorar muitas possibilidades, que são previsões e características apresentadas por Chiavenato e Sapiro (2003) como "pontos fortes e fracos" sobre um contexto ou negócio, para evitar problemas em processos e projetos. As informações separadas na ferramenta são também obtidas por observação, pesquisas e conversas, e organizadas para relacionar pontos opostos no trabalho, buscando 
estrategicamente posicionar uma iniciativa na melhor das condições. São identificadas na Figura 7 as forças (Strengths), oportunidades (Opportunities), fraquezas (Weaknesses) e ameaças (Threats) do processo de formação das peças das artesãs.

\begin{tabular}{|c|c|c|}
\hline \multicolumn{3}{|c|}{ Izabel Matos } \\
\hline & Forças & Fraquezas \\
\hline
\end{tabular}

Figura 7 - Análise aprofundada dos saberes e práticas de Izabel Matos. Fonte: Os autores

\subsection{Painel Semântico (Moodboard)}

O painel é composto por imagens que de acordo com Bonsiepe (2011) são instrumentos importantes para refletir e expressar ideias, representando as expectativas e imaginário cultural em relação ao que deve ser trabalhado. Também é uma ferramenta que traz inspirações para a construção de alternativas, separado em tópicos se necessário para facilitar a busca de referências. Também chamado de moodboard, pode ser adaptado enquanto aspectos visuais e práticos do projeto que ainda não foram definidos. Na Figura 8 pode ser observado o painel produzido sobre o Tambor de Crioula maranhense, produzindo parâmetros de cores, formas e elementos figurativos presentes nas roupas dos dançantes já representados na própria identidade visual do moodboard, por exemplo. 


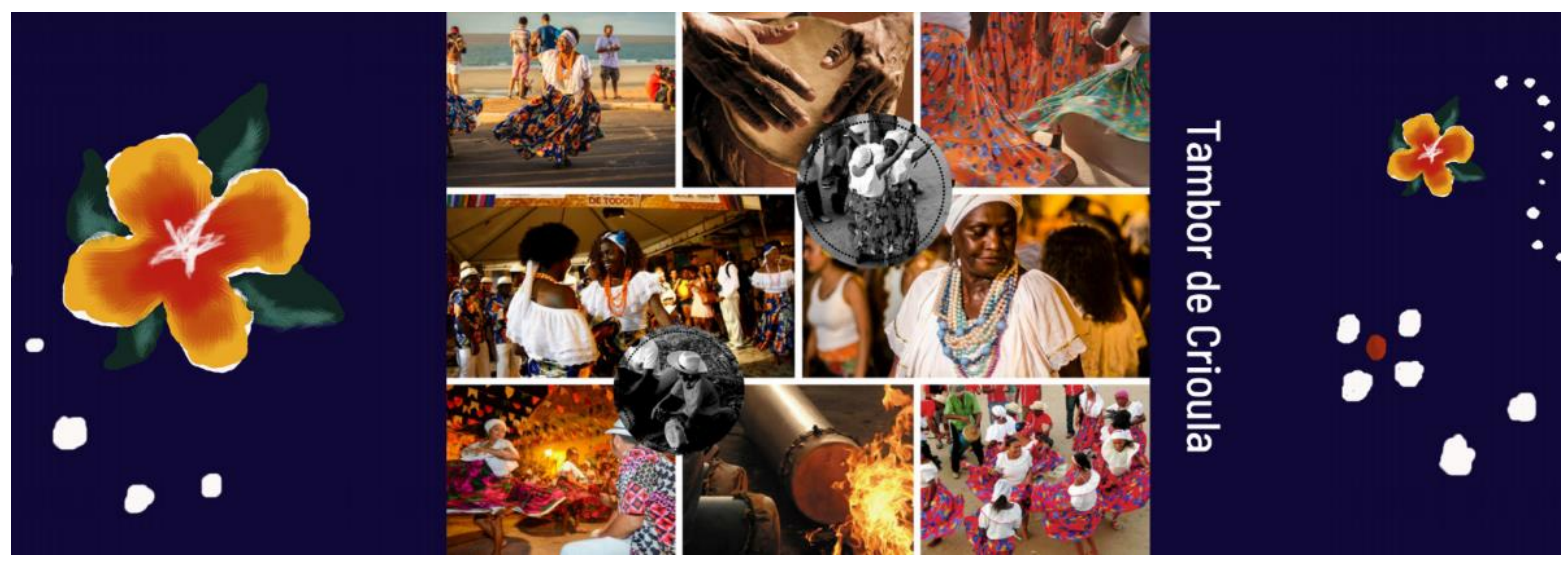

Figura 7 - Análise aprofundada dos saberes e práticas de Izabel Matos.

Fonte: Os autores

\section{Resultados}

O processo colaborativo resultou acima de tudo na elucidação de como saberes culturais e tradicionais podem ser trabalhados através de técnicas educacionais para a valorização dos mesmos. A transformação do barro, os diálogos sobre memória cultural (como o Tambor de Crioula) e a colaboração entre universidade e comunidade são exemplos destas vivências que permitiram um efetivo trabalho coletivo correspondente entre design e artesanato. Um dos objetos obtidos desta relação foi a produção dos alunos com Izabel Matos durante as oficinas de uma luminária em cerâmica como segue na Figura 8. Ela foi nomeada como "Luminária Pungada" em referência ao passo de dança do Tambor de Crioula e traz suas coreiras representadas no ritmo da brincadeira, com elementos alusivos ao tecido de Chita, como flores e elementos que representam a diversidade cultural maranhense.

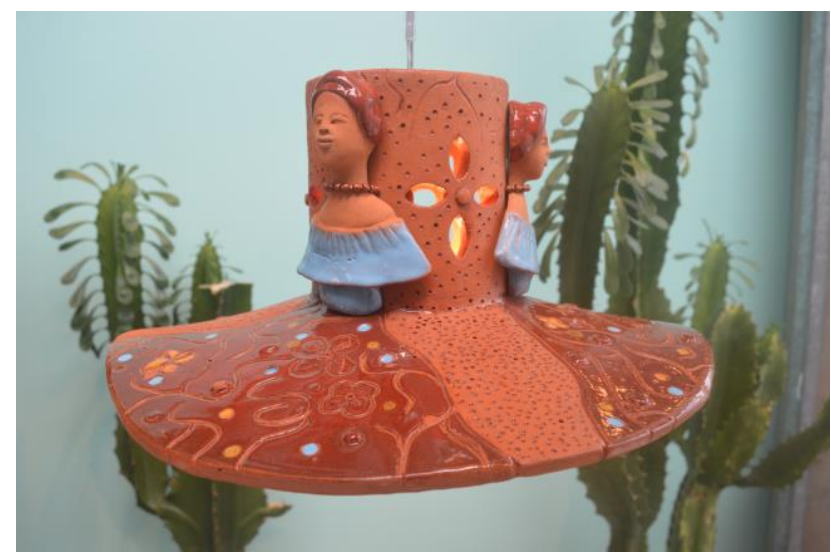

Figura 8 - Análise aprofundada dos saberes e práticas de Izabel Matos. Fonte: Os autores 
Outra alternativa para o repertório de produções que buscam valorizar o trabalho da ceramista e consequentemente evidenciar suas memórias culturais foi representar a produção em uma identidade visual. A partir das ferramentas metodológicas foi desenvolvida uma marca composta pelas mãos que moldam o barro, nas palavras de Izabel Matos, onde podemos observar duas mãos moldando o contorno de uma coreira, figura já citada do Tambor de Crioula e muito presente nas produções da artesã. Tal prática cultural também foi representada através das cores e texturas nas etiquetas, cartão de visitas e carimbos como seguem nas figuras a seguir, além de peças para redes sociais que concluem um pacote de material que alcança novos públicos quando divulgados virtualmente e acompanhando os trabalhos de Izabel para outros espaços quando adquiridos por turistas de outros estados do Brasil e outros países, carregando um produto feito por mãos que carregam histórias, saberes e tradições culturais, em um processo que Canclini (1983) descreve como trânsito intercultural.
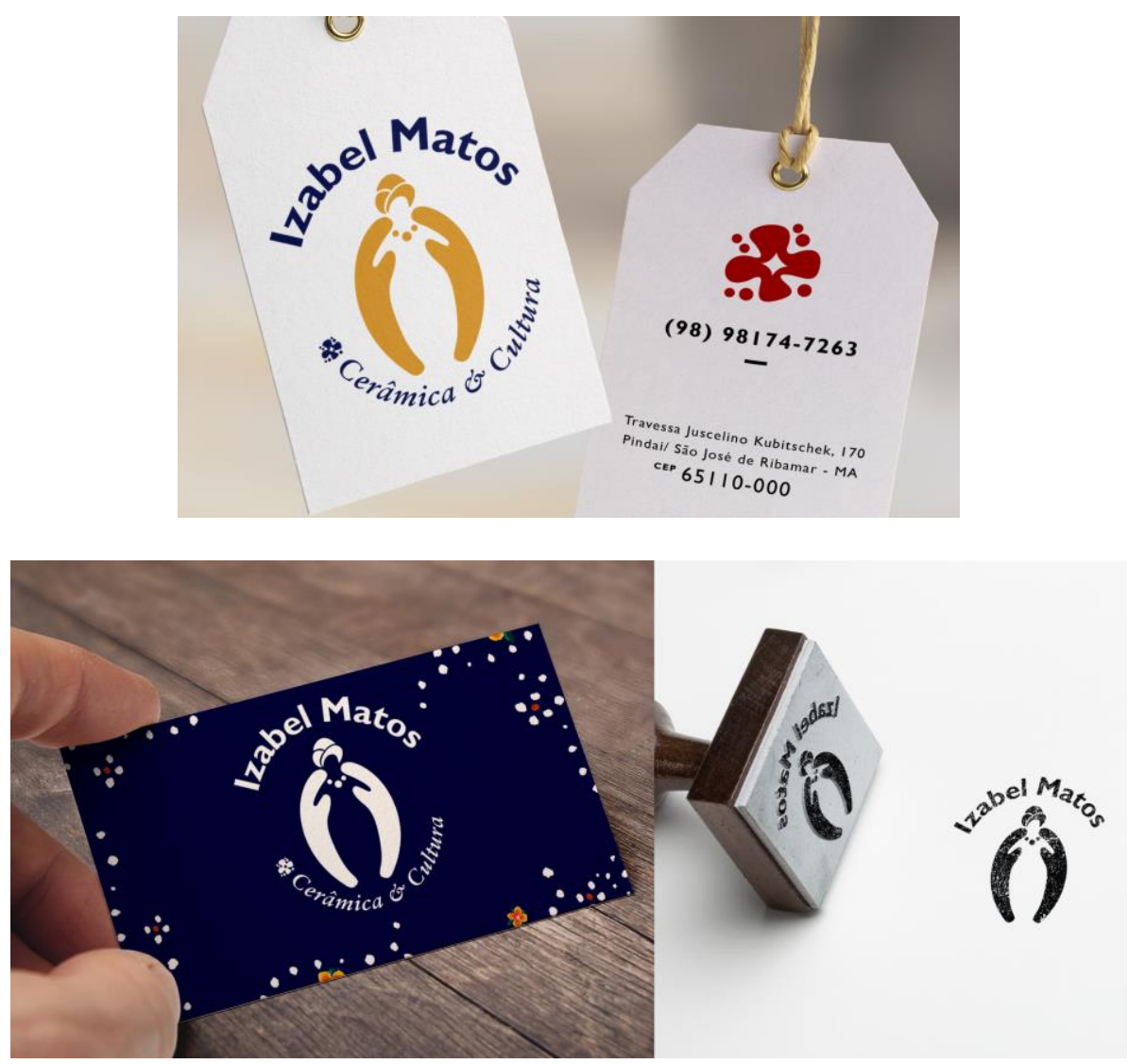

Figuras 9 e 10 - Etiquetas, cartão de visitas e carimbo para peças de Izabel Matos.

Fonte: Os autores 


\section{Conclusões}

O projeto possibilitou a consolidação da relação da Universidade com a comunidade por meio da parceria de alunos, professores e ceramistas, registrando a memória e a prática tradicional, sem impor técnicas, mas compreendendo, dialogando e inserindo interessados e beneficiados em todos os processos de pesquisa e desenvolvimento.

Nos diálogos e trabalhos realizados com Izabel Matos e as demais artesãs, entendemos como unir saberes técnicos e populares, preservando a cultura maranhense e afro brasileira. Desta forma é possível unir a criatividade, o repertório e os valores dos envolvidos em uma "busca por agregar valor a produtos, fortalecendo e estimulando a identidade local" (KRUCKEN, 2009, p.43).

As identidades visuais e produtos em cerâmica foram apenas uma parte integrante do processo, que buscou realizar uma experiência educacional e cultural entre estudantes e artesãs para integrar Design e Artesanato. Promover a colaboração entre universidade e comunidade para valorizar a cultura é um caminho viável para a divulgação e melhoria do mercado artesanal e preservação de manifestações e patrimônios imateriais.

\section{Referências}

BONSIEPE, G. Design, cultura e sociedade. São Paulo: Blucher, 2011.

BUZAN, T. Saber Pensar. Lisboa: Editorial Presença, 1996.

CANCLINI, N. G. As culturas populares no capitalismo. São Paulo: Editora Brasiliense, 1983.

CHIAVENATO, I.; SAPIRO, A. Planejamento Estratégico: fundamentos e aplicações. Rio de Janeiro: Elsevier, 2003.

COHEN, E. Authenticity and commoditization in tourism. In: ANNALS OD TOURISM RESEARCH, pp. 371-386, 1988, London.

HALBWACHS, Maurice. A Memória Coletiva. São Paulo: Centauro, 2006.

JUNIOR, D., 2018. Tambor De Crioula. [imagem] Disponível em: <https://www.flickr.com/photos/mturdestinos/albums/72157664777611897> [Acessado em 1 de Junho de 2020].

KRUCKEN, L. (2009). Design e território. 1st ed. São Paulo: Studio Nobel.

LIMA, Ricardo Gomes. Objetos: percursos e escritas culturais. São José dos Campos: Centro de Estudos de Cultura Popular; Fundação Cultural Cassiano Ricardo. 2010. 
TAMEKUNI, K. I. Metaprojeto: o design em busca da inovação por meio da reflexão. In: $11^{\circ}$ CONGRESSO BRASILEIRO DE PESQUISA E DESENVOLVIMENTO EM DESIGN, Gramado, 2014.

TAPSCOTT, D.; TICOLL, D. A empresa transparente. São Paulo: M. Books do Brasil, 2005. 